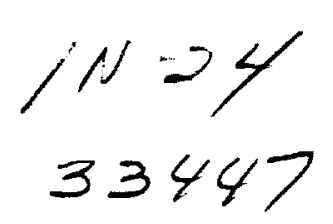

NASA TECHNICAL MEMORANDUM 104131

(NASA-TM-104131) EFFECT OF FIBER-MATPIX

DEBTINIING ON NUTCHED STRENGTH OF TITANIUM

p33

METAL MATPIX COMPOSITES (NASA) 33 .

CSCL $110 \quad$ Unclas

G3/24 0033447

\title{
EFFECT OF FIBER-MATRIX DEBONDING ON NOTCHED STRENGTH OF TITANIUM METAL MATRIX COMPOSITES
}

C. A. Bigelow and W. S. Johnson

\section{August 1991}

Presented at the ASTM 23rd National Symposium on Fracture Mechanics, June 18-20, 1991, College Station, Texas

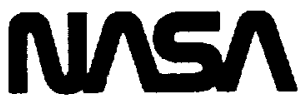

National Aeronautics and

Space Administration

Langley Research Center

Hampton, Virginia 23665 


\section{ABSTRACT}

Two specimen configurations of a [0/90] $2 \mathrm{~s}$ SCS-6/Ti-15-3 laminate were tested and analyzed: a center hole (CH) specimen and a double edge notch (DEN) specimen. The two specimen configurations failed at similar stress levels in spite of the large difference in the stress concentration factors for the two geometries. Microscopic examinations of the failure surfaces indicated more fiber-matrix debonding at the notch tip in the DEN specimen than in the $\mathrm{CH}$ specimen. Based on the experimental results, it was hypothesized that the radial stresses that developed at the fiber-matrix interface ahead of the notch tip in the DEN specimen caused fiber-matrix debonding in the $0^{\circ}$ plies, thus, lowering the stress concentration in the DEN specimen to a level comparable to that of the $\mathrm{CH}$ specimen.

Two analytical techniques, a three-dimensional finite element analysis and a macro-micromechanical analysis were used to predict the overall stressdeformation behavior and the notch-tip fiber-matrix interface stresses in both configurations. The micromechanical analysis predicted radial stresses next to the notch in the DEN configuration that were nearly 7 times as large as those predicted for the $\mathrm{CH}$ configuration. The overall stress-deformation response of both configurations was accurately predicted when debonding of the $90^{\circ}$ plies was included. Predictions of the axial stress in the notch-tip $0^{\circ}$ fiber correlated well with the specimen static strength when fiber-matrix debonding of $0^{\circ}$ plies was included for the DEN specimen. The results shown indicate that a first fiber failure criteria based on the axial stress in the first intact $0^{\circ}$ fiber can predict the static strength of notched specimens when interfacial damage is modeled.

\section{INTRODUCTION}

Fiber-matrix interfaces can play a key role in the mechanical behavior of continuous fiber-reinforced metal matrix composites (MMC's) [1]. Interfaces govern the mode and extent of load transfer between the fiber and matrix. When the interfaces are strong and transmit all loads fully, isolated fiber fractures 
tend to spread more rapidly to other fibers, and hasten failure [2]. Continuous fiber-reinforced composites can often be made more damage tolerant by decoupling Eaciured fibers from their nelghbors through controlled interfacial failure. It may be possible to tailor the strength and toughness of the interface to decouple broken fibers from their surroundings. To accomplish such a feat, it is first necessary to understand interfacial behavior and debonding in MMC's. Early work with boron/aluminum (B/Al) MMC's showed that in this low yleld matrix, the interface was not a critical factor. Instead extensive yielding of the matrix occurred at the notch tips, such that specimens with sharp notches and center holes failed at simflar stress levels [3]. In brittle polymeric matrix composites, simflar notch insensitive results have been observed for quasi-isotropic laminates [4]. However, in polymeric composites, the notch insensitivity was caused by extensive matrix cracking and delaminations near the crack tip that significantly reduced the local stress concentration [5]. The fiber-matrix interface can play a particularly significant role in MMC's with a matrix having a high yield strength, such as the SCS-6/Ti-15-3 system currently being investigated. Debonding of the fiber-matrix interface is a primary damage mechanism in SCS-6/Ti-15-3 composites [1]. Proper modeling of interfacial debonding is needed to accurately predict composite fracture behavior. To study the stress state governing fiber-matrix debonding, a micromechanics analysis is required.

The objective of the present work is to predict the static strength of notched SCS-6/Ti-15-3 composites. Two specimen configurations of a $[0 / 90]_{2 s}$ SCS-6/Ti-15-3 laminate were tested and analyzed: a center hole (CH) specimen and a double edge notch (DEN) specimen. Microscopic examinations of the failure surfaces in both configurations were made. Two analytical techniques, a threedimensional finite element analysis (PAFAC) and a macro-micromechanical analysis (MMA) were used to analyze the behavior of both the DEN and $\mathrm{CH}$ specimens. The MMA was used to analyze the stresses in the notch-tip element in the interior $0^{\circ}$ ply in both the DEN and $\mathrm{CH}$ specimens to determine the fiber-matrix interface stress state for perfectly bonded fibers. PAFAC was used to predict the global 
stress-deformation response with interfacial debonding in the $90^{\circ}$ plies. PAFAC was also used to predict the fiber axial stresses in the first $0^{\circ}$ fiber next to the notch for the two configurations with interfacial debonding in the $90^{\circ}$ and $0^{\circ}$ plies. The static strengths of each specimen were compared to the predictions of first fiber failure in the $0^{\circ}$ plies.

\section{MATERIALS AND TEST PROCEDURES \\ Materials and Specimens}

The alloy $\mathrm{Ti}-15-3$, a shortened designation for $\mathrm{Ti}-15 \mathrm{~V}-3 \mathrm{Cr}-3 \mathrm{Al}-3 \mathrm{Sn}$, is a metastable beta strip alloy [6]. The composite laminates were made by hot-pressing Ti-15-3 foils between unidirectional tapes of silicon-carbide fibers held in place with molybdenum wire. The manufacturer's designation for these silicon-carbide fibers is SCS-6. The fiber diameter is $0.14 \mathrm{~mm}$. Two specimen configurations of the SCS-6/TI-15-3 material were tested: a $\mathrm{CH}$ specimen and a DEN specimen. The two specimens were cut from a panel of $[0 / 90]_{2}$ material. Each specimen consisted of eight plies and was approximately $1.67 \mathrm{~mm}$ thick. The fiber volume fraction was approximately 398 for both specimens.

Each specimen was $19.1-\mathrm{mm}$ wide and $152.4-\mathrm{mm}$ long. One specimen ( $\mathrm{CH}$ ) had a circular hole with a diameter of $6.35 \mathrm{~mm}$ cut in the center of the specimen. The other specimen (DEN) had two edge notches cut on the sides of the specimen using electro-discharge machining. Each notch had a length of $3.18 \mathrm{~mm}$ with a width of $0.25 \mathrm{~mm}$ and a notch tip radius of $0.125 \mathrm{~mm}$. The two specimen configurations are shown in Figure 1. Both specimens were tested in the as-fabricated condition.

\section{Testing Techniques}

The tests were conducted on a $89 \mathrm{kN}$ servo-hydraulic test stand. Load control was used with a loading rate of approximately $.89 \mathrm{kN} / \mathrm{s}$. Both specimens were pulled statically in tension to failure. An extensometer with a $25.4 \mathrm{~mm}$ gage length was mounted in the center of each specimen to record the deformation. An X-Y recorder was used to record the load-deformation response of the specimen using the load cell and extensometer output. Global strains of the specimens were calculated from the extensometer output. 


\section{ANALYTICAL TECHNIQUES}

Two analytical techniques were used to model and predict various aspects of she specimen and material behavior. The first, a three-dimensional finite element analysis (PAFAC [7]), was used to analyze the global behavior of both notched SCS-6/Ti-15-3 specimens with interfacial debonding and yielding. The second, a macro-micromechanical analysis (MMA) [8], was used to analyze notchtip stress states in both the $\mathrm{DEN}$ and $\mathrm{CH}$ specimens with perfectly bonded fibers. Both analytical techniques are based on constituent properties. The fiber and matrix properties used in both analyses are given in Table 1 . The two techniques will be described in more detail in the following sections.

Three-Dimensional Analysis, PAFAC

The three-dimensional finite element analysis PAFAC ( Analysis of Composites) was used to analyze the overall behavior of both specimens. The analysis uses the vanishing-fiber-diameter material model [9] to account for the elastic-plastic behavior of the matrix and the elastic behavior of the fiber. PAFAC uses an eight-noded hexahedral element; each element represents a unidirectional composite material whose fibers are arbitrarily oriented in the structural coordinate system. Using this material model, the analysis calculates the fiber and laminate stresses and predicts when ylelding occurs in each element of the finite element mesh. The PAFAC analysis does not account for the thermal residual stresses that are present in this material due to the fabrication process.

Figure 2 shows a plan view of each of the finite element meshes that were used to model the DEN and $\mathrm{CH}$ specimens. In both cases, only one-eighth of the specimen was modeled due to symmetry. The mesh for DEN specimen contained approximately 2600 nodes and 1600 elements; the notch was modeled as a rectangle. The mesh for the $\mathrm{CH}$ specimen contained approximately 1500 nodes and 1040 elements. Each ply of the $[0 / 90]_{2 s}$ laminate was modeled with one layer of elements. Thus, each mesh contained four layers of the elements through the thickness (Z-direction). The smallest elements, located next to the notch, were sized to represent one fiber spacing. This fiber spacing was calculated using 
the fiber volume fraction $\left(v_{f}-398\right)$, the fiber diameter $\left(d_{f}-0.14 \mathrm{~mm}\right)$, and the ply thickness $(t-0.209 \mathrm{~mm})$. A uniform stress was applied to the end of each specimen to simulate loading and the end of the model was constrained to displace uniformly.

Earlier work with unnotched SCS-6/Ti-15-3 laminates [1] indicated interfacial debonding in $90^{\circ}$ plies at very low load levels. To model this phenomena, PAFAC was modified to include a failure criterion to approximate interfacial debonding in the $90^{\circ}$ plies. Using the discrete fiber-matrix model described in the Appendix, the transverse modulus of a unidirectional laminate with a completely debonded fiber-matrix interface was calculated. When the transverse stress in the elements in the $90^{\circ}$ plies reached a specified critical value, the material properties of the $90^{\circ}$ plies were modified to represent an isotropic material with an elastic modulus equal to the transverse modulus of a unidirectional laminate with a completely debonded interface. The effect of modeling an orthotropic layer with an isotropic material model was examined and is discussed in the Appendix. The critical transverse stress was chosen to be $155 \mathrm{MPa}$ based on experimental observations of unnotched $[90]_{8}$ laminates [1]. The predicted stress-deformation curves with debonding of the $90^{\circ}$ plies will be compared to the experimental data for both the DEN and $\mathrm{CH}$ specimens.

The PAFAC analysis was also modified to account for interface debonding in the $0^{\circ}$ plies at the notch tip in the DEN specimen; the approximation used is shown schematically in Figure 3. The original mesh at the notch tip for the DEN model is shown in Figure 3(a), where the mesh contains one layer of elements per ply and the elements at the notch tip are one fiber spacing wide. The fibers are shown for reference only; since the material model in PAFAC is homogeneous, it cannot model the fibers discretely. The elements next to the notch tip, which were one fiber spacing wide, were each divided into two elements. Then additional layers of elements were added such that each $0^{\circ}$ ply was modeled with three layers of elements, as opposed to one layer used previously. The material properties of the additional elements were specified so that the elements next to the notch and between each layer were isotropic with the material properties 
of the matrix. The isotropic elements added between the $0^{\circ}$ and $90^{\circ}$ plies were $0.0345-\mathrm{mm}$ thick. The remaining elements in the $0^{\circ}$ plies were modeled as composite elements with appropriately higher fiber volume fractions. Adding the isotropic layers does not affect the overall stress-deformation response of the laminate. To model the effects of fiber-matrix debonding of the $0^{\circ}$ fiber next to the notch, the elastic modulus of the isotropic elements in both $0^{\circ}$ plies indicated by the shaded areas in Figures $3(\mathrm{~b})$ was reduced. Poisson's ratio was unchanged. Predictions of the notch-tip $0^{\circ}$ fiber stress were made reducing the elastic modulus by a factor of 10,100 and 1000 to determine the sensitivity of fiber stress to the reduction factor.

In the PAFAC analysis, it was also possible to vary the number of elements with the reduced modulus in the longitudinal direction (parallel to the $0^{\circ}$ fibers). The effect on the $0^{\circ}$ fiber stress due to varying the number of elements in the longitudinal direction with reduced moduli was also examined. Varying the number of elements in this direction would be equivalent to modeling different debond lengths for the $0^{\circ}$ fiber at the notch tip.

Macro-Micromechanical Analysis (MMA)

The second analytical technique, the macro-micromechanical analysis (MMA) developed by Bigelow and Naik [8], was used to analyze notch-tip stress states in both the $\mathrm{DEN}$ and $\mathrm{CH}$ specimens. The macro-micromechanical analysis combines the 3D homogeneous, orthotropic finite element analysis (PAFAC) of the notched specimen and a discrete fiber-matrix (DFM) micromechanics model of a single fiber. The MSC/NASTRAN finite element code [10] was used to analyze the DFM model. The MMA was used to calculate the stresses in the notch-tip element in the interior $0^{\circ}$ ply of the $[0 / 90]_{2 s}$ laminate assuming a perfectly bonded fibermatrix interface. The interior $0^{\circ}$ ply was the location of the highest axial fiber stress predicted by the PAFAC analyses of the specimens. As mentioned, in both specimen configurations, the finite element mesh was designed so that the dimensions of the elements next to the notch corresponded to a single fiber spacing. A plan view of the finite element mesh, and its dimensions, that was used to model the notch-tip element for both configurations is shown in Figure 
4. A schematic view of the macro-micro interface used in the MMA for the DEN specimen is shown in Figure 5. Displacement boundary conditions from the macrolevel analysis are applied to the micro-level DFM mesh to simulate the stress state next to the notch. A similar concept was used for the $\mathrm{CH}$ specimen. The micro-level model shown in Figure 4 was used for both the DEN and CH configurations. Thermal residual stresses were not included in this analysis.

\section{RESULTS AND DISCUSSION \\ Experimental Observations}

The two specimen configurations failed at similar stress levels in spite of large differences in their stress concentration factors. The elastic stress concentrations $\mathrm{K}_{\mathrm{T}}$ are 3.7 for the $\mathrm{CH}$ specimen and 5.7 for the DEN specimen. These values of $\mathrm{K}_{\mathrm{T}}$ were calculated, assuming perfectly bonded fiber, using the PAFAC analysis and the meshes shown in Figure 2. The $K_{T}$ for the DEN is roughly one and one half times that of the $\mathrm{K}_{\mathrm{T}}$ of the $\mathrm{CH}$ configuration. The static strength of the DEN specimen was $520 \mathrm{MPa}$, for the $\mathrm{CH}$ specimen the static strength was $501 \mathrm{MPa}$. These strengths were unexpectedly close given the difference in the $\mathrm{K}_{\mathrm{T}}$ 's .

The failure surfaces next to the notch were examined microscopically for both specimen configurations in order to identify the fallure mechanisms. The surface of each specimen was polished to reveal the first layer of $0^{\circ}$ fibers. Typical photographs for each configuration are shown in Figure 6 . In these photographs, the light gray area is matrix and the darker gray areas are fibers. In Figure 6(a) the carbon core in the SCS-6 fiber and the molybdenum wire are visible. Figure 6(a) shows the area just ahead of the notch for the DEN specimen. The first fiber ahead of the notch was damaged during the machining of the notch, thus, this fiber probably falled rather early in the loading history. The next fiber failed away from the plane of the notch, exhibiting fiber pullout; this type behavior would be expected if fiber-matrix debonding had occurred over that length of the fiber. In this case, the fiber-matrix debond length is three to four fiber diameters in length. Figure 6(b) shows an area 
next to the hole for the $\mathrm{CH}$ specimen. Minimal fiber pullout is seen next to the hole, indicating that significant fiber-matrix debonding was not present prior to specimen failure.

Based on the experimental results, it was hypothesized that tensile radial stresses at the fiber-matrix interface ahead of the notch tip in the DEN specimen were large enough to cause extensive fiber-matrix debonding in the $0^{\circ}$ plies, thus, lowering the stress concentration in the DEN specimen. Both analytical techniques, PAFAC and the MMA, were used to examine the hypothesis. The MMA was used to analyze the stresses in the notch-tip element in the interior $0^{\circ} \mathrm{ply}$ in both the DEN and $\mathrm{CH}$ specimens to determine the fiber-matrix interface stress state. PAFAC was used for two analyses. First, the global stress-deformation response was predicted including matrix yielding and interfacial debonding in the $90^{\circ}$ plies. Second, the fiber axial stresses in the first $0^{\circ}$ fiber next to the notch were predicted for the two configurations. The effects of modeling interfacial debonding in the $90^{\circ}$ and $0^{\circ}$ plies on the axial stress in the notch-tip $0^{\circ}$ fiber were examined.

\section{Interface Stresses}

For a unit applied stress ( $\mathrm{S}=1 \mathrm{MPa}$ ), the MMA predicted the stresses shown In Figure 7 and 8 for the DEN and $\mathrm{CH}$ specimens, respectively. The stresses shown do not include the thermal residual stresses which would present due to the fabrication of the composite. The stresses presented are the stresses in the matrix at the fiber-matrix interface calculated at the finite element nodal points. For comparison, the matrix stresses in the interior $0^{\circ}$ ply in an unnotched $[0 / 90]_{2 s}$ specimen due to a unit applied stress are shown in Figure 9. The stresses are presented with respect to the cylindrical coordinate system shown. Stresses are shown for the plane of symmetry on the XZ plane, i.e. through the center line of the notch or hole. Due to symmetry the shear stresses are zero on this plane; thus, only the three normal stress components will be presented. For the two notched configurations, $\theta=180^{\circ}$ is the side of the fiber next to the notch. 
In all three configurations, the peak values of the normal stresses occur at $\theta=180^{\circ}$. In the $\mathrm{DEN}$ and $\mathrm{CH}$ configurations, the stresses are nearly symmetric about $\theta=180^{\circ}$. This is expected since the stresses were calculated for an interior ply. In the unnotched laminate (Figure 9), the stresses are symmetric about $\theta=0^{\circ}$ and $180^{\circ}$. In fact, for the unnotched laminate, it was sufficlent to model only a quarter of the fiber. However, results are presented for $0^{\circ} \leq \theta \geq 360^{\circ}$ for comparison with the notched laminate results in Figures 7 and 8 .

All three stress components shown are largest for the DEN specimen and the smallest for the unnotched laminate. The gradient in the stress distribution is also much larger for the DEN specimen than the $\mathrm{CH}$ specimen. Consider for example the axial component. The axial stress in the DEN specimen ranges from a peak value of $5.2 \mathrm{MPa}$ to a minimum of $2.2 \mathrm{MPa}$, whereas in the $\mathrm{CH}$ specimen, the axial stress only ranges from 2.2 to $1.6 \mathrm{MPa}$. This is due, of course, to the higher stress concentration of the DEN specimen. Likewise, the peak value of the radial stress component is much larger relative to the hoop and axial stress components in the DEN specimen compared to the $\mathrm{CH}$ specimen. In the DEN specimen, the maximum radial stress is 1.67 times the hoop stress and .87 times the axial stress. In the $\mathrm{CH}$ specimen, the maximum radial stress is 1.24 times the hoop stress and only .25 times the axtal stress. It is also interesting to note that the radial stresses for the DEN configuration (Figure 7) are tensile for all values of $\theta$, whereas for the $\mathrm{CH}$ configurations, the radial stresses are tensile only from approximately $110^{\circ}$ to $250^{\circ}$ (Figure 8 ), and for the unnotched laminate, the radial stresses are compressive for all values of $\theta$ (Figure 9). For interfacial failure, the stress component of primary concern is the radial stress. The peak values of the radial matrix stresses due to a remote stress of $1 \mathrm{MPa}$ are 4.5 and $.67 \mathrm{MPa}$ for the $\mathrm{DEN}$ and $\mathrm{CH}$ specimens, respectively. The peak value of the radial stress for the unnotched laminate is $-0.17 \mathrm{MPa}$. Thus, for a given interfacial strength, the interface in the DEN specimen will debond much earlier in the loading history than in the $\mathrm{CH}$ specimen. Conversely, for a given load, the $0^{\circ}$ fibers next to the notch in the DEN specimen are more 
likely to have debonded than in the $\mathrm{CH}$ specimen. Since an interfacial strength is not available, it is not possible to predict when the interface will debond. Based on the stresses shown in Figures 7 and 8 and the evidence of a weak interface in the SCS-6/Ti-15-3 material [1], it is likely that much more debonding of the $0^{\circ}$ plies occurred in the DEN than the $\mathrm{CH}$ specimen. In fact, based on the micrographics presented in Figure 6 , the $0^{\circ}$ plies probably did not debond in the CH specimen.

\section{Calculations With Interface Debonding}

The predicted and experimental stress-deformation curves for both specimens are shown in Figure 10. The PAFAC predictions were made including interfacial debonding in the $90^{\circ}$ plies. From the DFM analysis described in the Appendix, the transverse modulus of a unidirectional laminate with a completely debonded interface was found to be $50.1 \mathrm{GPa}$. As described previously, a simplistic fallure criterion was incorporated in the PAFAC analysis to simulate a debonded interface in the $90^{\circ}$ plies. After the critical transverse stress (155 MPa) was reached in any finite element with an orientation of $90^{\circ}$, that element was then modeled as isotropic material with an elastic modulus of $50.1 \mathrm{GPa}$. By modifying the material properties of the $90^{\circ}$ plies to simulate the failed interfaces, the predicted stress-deformation behavior agreed quite well with the experimental results for $\mathrm{CH}$ specimen and reasonably well for the DEN specimen.

The PAFAC analysis was then used to determine the effect of debonding in the $0^{\circ}$ plies on the notch-tip fiber stress concentrations. The axial fiber stresses in the element next to the notch in the interior $0^{\circ}$ ply were predicted for both the DEN and $\mathrm{CH}$ specimens using the modified material properties for the $90^{\circ}$ plies (1.e., debonded 90 fiber-matrix interfaces) as described above. Figure 11 shows the predictions of the $0^{\circ}$ fiber stress in the first element next to the notch as a function of applied stress for the DEN and CH specimens assuming no debonding of the $0^{\circ}$ plies. The horizontal dashed line indicates an assumed fiber strength of $4200 \mathrm{MPa}$, and the two vertical dash-dotted lines show the experimental strengths of the two specimens. The fiber strength was calculated from the strain to fallure of an unnotched $[0 / 90]_{2 s}$ coupon $\left(\epsilon_{u l t}=0.0105\right.$ 
$\mathrm{mm} / \mathrm{mm})$. The solid and dashed lines indicate the predicted $0^{\circ}$ fiber stress with no debonding in the $0^{\circ}$ plies for the DEN and $\mathrm{CH}$ specimens, respectively. If the strength of the first $0^{\circ}$ fiber is used as a fallure criteria, the analysis predicts the strength of the $\mathrm{CH}$ specimen quite well. However, the strength of the DEN specimen is significantly underpredicted. Earlier work with B/Al [3] indicated that a first $0^{\circ}$ fiber fallure criteria accurately predicted the static strengths of a variety of notched specimens.

Based on the earlier hypothesis of debonding at the notch tip in the DEN specimen, the approximation described earlier was made using the PAFAC analysis to model the effects of debonding in the $0^{\circ}$ plies in the DEN configuration. As shown in Figure $3(\mathrm{~b})$, the elastic modulus of the elements indicated by the shaded areas was reduced by a factor of 10,100 and 1000 to approximate the interface debonding of the notch-tip $0^{\circ}$ fiber in the DEN specimen. Little difference in the $0^{\circ}$ axial fiber stress (less than 18) was seen whether the modulus was reduced by 10,100 , or 1000 so results are shown for a reduction factor of 1000 . The number of elements parallel to the $0^{\circ}$ fiber direction with a reduced modulus was varied to represent different debond lengths. This is shown schematically in Figure 12 for the various numbers of elements modified.

The axial notch-tip $0^{\circ}$ fiber stress in the interior $0^{\circ}$ ply for both configurations is shown in Figure 13. The fiber stresses shown in Figure 13 were calculated with interfacial debonding of the $90^{\circ}$ plies. In addition, the calculations for the DEN specimen include the interfacial debonding of the notchtip elements in the $0^{\circ}$ plies. The two solid lines are the predictions made for no debonding of the $0^{\circ}$ plies repeated from Figure 11. Reducing the modulus of only one element (dashed line) reduced the fiber stress in the DEN specimen considerably, as shown in Figure 13. Reducing the modulus of only 2 elements caused the $0^{\circ}$ fiber stress to drop nearly to the level of the $\mathrm{CH}$ configuration. A two element length is equivalent to a debond length of 3.5 flber diameters. This debond length is in good agreement with the micrographs showing a debond length of three to four fiber diameters (Figure $6(a)$ ). By reducing the modulus of four or more elements, the $0^{\circ}$ fiber stress in the notch-tip element in DEN 
specimen was reduced to a level below that of the $\mathrm{CH}$ configuration. The results show in Figure 13 agree with predictions made using a two-dimensional shear lag model of a unidirectional composite [11] showing that any damage will bring the solutions for a notch and a hole closer together. From Figure 13, a first fiber failure criteria based on the axial stress of the notch-tip $0^{\circ}$ fiber would predict the strength of the $\mathrm{CH}$ specimen to be $490 \mathrm{MPa}$ and the strength of the DEN specimen to be from 320 to $560 \mathrm{MPa}$, depending upon the debond length modeled in the $0^{\circ}$ plies of the DEN specimen. For a debond length of 3.5 flbers (2 elements) in the $0^{\circ}$ plies next to the notch, the PAFAC analysis predicts a strength of $500 \mathrm{MPa}$ for the DEN configuration. The strength prediction correlates reasonably well with the experimental strengths of $520 \mathrm{MPa}$ observed for the DEN specimen. As mentioned earlier, the thermal residual stresses that are present in this material due to the fabrication process were not accounted for in the analyses. A compressive axial stress would be present in the $0^{\circ}$ fibers due to the temperature change during the fabrication process. However, the same thermal residual stress state would be present in both the CH and DEN specimens, and in the unnotched specimen used to determine the fiber strength. The results shown indicate that the axial stress in the first intact $0^{\circ}$ fiber may dictate the static strength of the specimen and a first fiber failure criteria would predict specimen strengths when interfacial debonding is modeled.

\section{CONCLUDING REMARKS}

The static notched strengths of $[0 / 90]_{2 s}$ SCS-6/Ti-15-3 laminates were predicted based on the stress in the notch-tip $0^{\circ}$ fiber. Two specimen configurations of a $[0 / 90]_{2 s}$ SCS-6/Ti-15-3 laminate were tested and analyzed: a center hole $(\mathrm{CH})$ specimen and a double edge notch (DEN) specimen. The two specimen configurations failed at similar stress levels in spite of the large difference in the stress concentration factors for the two geometries. Microscopic examinations of the failure surfaces for both configurations showed fiber pullout for the DEN specimen, indicating fiber-matrix debonding had occurred. Minimal fiber pullout was seen in the $\mathrm{CH}$ specimen. Based on the 
experimental results, it was hypothesized that the radial stresses that developed at the fiber-matrix interface ahead of the slit tip in the DEN specimen were large enough to cause fiber-matrix debonding in the $0^{\circ}$ plies, thus, lowering the stress concentration in the DEN specimen to a level comparable to that of the $\mathrm{CH}$ specimen.

Two analytical techniques, a three-dimensional finite element analysis (PAFAC) and a macro-micromechanical analysis (MMA) were used to predict the overall stress-deformation behavior and the notch-tip fiber-matrix interface stresses in both configurations. The MMA predicted radial stresses next to the notch in the DEN configuration that were nearly 7 times as large as those predicted for the $\mathrm{CH}$ configuration. Thus, fiber-matrix debonding in the $0^{\circ}$ plies will occur much earlier in the loading history for the DEN specimen and, for a given stress level, more fiber-matrix debonding will occur in the DEN specimen than in the $\mathrm{CH}$ specimen. The overall stress-deformation response of both specimens was accurately predicted when interfacial failure of the $90^{\circ}$ plies was included in the analysis. The modulus of the $90^{\circ}$ ply with failed interfaces was determined using a discrete fiber-matrix (DFM) model containing gap elements. By reducing the modulus of elements at the notch tip to simulate debonding next to the notch in the $0^{\circ}$ plies, predictions of notch-tip $0^{\circ}$ fiber stress for the DEN configuration were reduced to a level comparable to that of the fiber stress in the $\mathrm{CH}$ configuration, indicating that fiber-matrix debonding in the DEN specimen could reduce the notch-tip stress sufficiently so that both configurations would have similar strengths. When the interfacial debonding of the $90^{\circ}$ plies and the notch-tip $0^{\circ}$ plies (in the DEN specimen) was modeled, the axial stress in the first intact $0^{\circ}$ fiber correlated well with the specimen static strength for both specimen configurations. The analyses assumed no significant debonding in the $0^{\circ}$ plies in the $\mathrm{CH}$ specimen. The analyses also did not account for thermal residual stresses in the material. However, the same thermal residual stress state would be present in both the $\mathrm{CH}$ and $\mathrm{DEN}$ specimens, and in the unnotched specimen used to determine the fiber strength. The results shown indicate that a first fiber failure criteria based on the axial stress in 
the first intact $0^{\circ}$ fiber can predict the static strength of notched specimens then interfacial damage is modeled.

\section{REFERENCES}

1. Johnson, W. S.; Lubowinski, S. J.; and Highsmith, A. L.: Mechanical Characterization of Unnotched $\mathrm{SCS}_{6} / \mathrm{Ti}-15-3$ Metal Matrix Composites at Room Temperature. Thermal and Mechanical Behavior of Metal Matrix and Ceramic Matrix Composites, ASTM STP 1080 , J. M. Kennedy, H. H. Moeller, and W. S. Johnson, Eds, American Society for Testing and Materials, Philadelphia, 1990, pp. $193-218$.

2. Na1k, R. A. ; and Pollock, W. D. ; and Johnson, W. S. : Effect of a High Temperature Cycle on the Mechanical Properties of Silicon Carbide/Titanium Metal Matrix Composites. Journal of Materials Sclence. Vol. 26, 1991, pp.
2913-2920.

3. Johnson, W. S.; Bigelow, C. A. ; and BaheI-El-Din, Y. A.: Experimental and Analytical Investigation of the Fracture Processes of Boron/Aluminum Laminates Containing Notches, NASA TP-2187, National Aeronautics and Space Administration, Washington, DC, 1983.

4. Daniel, I. M.: Failure Mechanisms and Fracture of Composite Laminates with Stress Concentrations. Proceedings of the VIIth International Conference on Experimental Stress Analysis, Haifa, Israel, August 23-27, 1982, pp. 120 .

5. Harris, C. E.; and Morris, D. H.: A Fractographic Investigation of the Influence of Stacking Sequence on the Strength of Notched Laminated Composites. Fractography of Modern Engineering Materials: Composites and Metals. ASTM STP 948, J, E. Masters and J.J. Au, Eds., American Society for Testing and Materials, 1987, pp. 131-i53.

6. Rosenberg, H. W.: Ti-15-3: A New Cold-Formable Sheet Titanium Alloy. Journal of Metals, Vol. 35, No. 11, Nov. 1986, pp. 30-34.

7. Bigelow, C. A.; and Bahei-El-Din, Y. A.: Plastic and Failure Analysis of Composites (PAFAC). LAR-13183, COSMIC, University of Georgia, 1983.

8. Bigelow, C. A. ; and Naik, R. A.: A Macro-Micromechanics Analysis of a Notched Metal Matrix Composite. NASA TM-102728, National Aeronautics and Space Administration, Washington, DC, Sept, 1990.

9. Bahe1-El-Din, Y. A.; and Dvorak, G. J.: Plasticity Analysis of Laminated Composite Plates. Journal of Applied Mechanics, American Society of Mechanical Engineers, Vol. 49, 1982, pp. 740-746.

10. MSC/NASTRAN, Version 6.6, MacNeal-Schwendler Corporation, 1991.

11. Goree, J. G.; Dharani, L. R.; and Jones W. F.: Mathematical Modeling of Damage in Unidirectional Composites. NASA Contractor Report 3453, August 1981 . 
APPENDIX - INTERFACIAL DEBONDING OF A UNIDIRECTIONAL LAMINATE

In tests of unnotched laminates of the SCS-6/Ti-15-3 material, a knee was seen in the stress-deformation response. This knee occurred well below the yield strength of the matrix material and was found to be due to debonding of the fiber-matrix interface in the $90^{\circ}$ plies [1]. A DFM model assuming an infinitely repeating rectangular array of fibers was used to analyze debonding of a unidirectional laminate. MSC/NASTRAN [10] was used for the finite element analysis. The ply thickness $(0.194 \mathrm{~mm})$, the fiber volume fraction (32.58), and the fiber diameter $(0.14 \mathrm{~mm})$ were used to calculate the dimensions of the model. The ply thickness, the fiber volume fraction, and the fiber diameter are typical for the SCS-6/Ti-15-3 material tested in [1]. A plan view of the DFM model is shown in Figure Al. In the DFM model, the debonded interface was modeled using the gap elements available in MSC/NASTRAN. Gap elements are nonlinear elements which may have significant compression and shear forces only if the gap is closed. The gap elements were placed between the fiber and matrix and given a zero length. Upon loading, the gap elements have zero stiffness when the gap opens and the same stiffness as the fibers if the gap remains closed, thus, modeling a failed interface. With the completely debonded interface, the modulus of the unidirectional laminate was calculated by loading the DFM model with the gap elements with a uniform stress applied in the transverse direction, as shown in Figure Al. The modulus was calculated from the slope of the stressdeformation curve. The transverse modulus of a unidirectional laminate with a debonded interface was calculated to be $50.1 \mathrm{GPa}$. This value of the transverse modulus is lower than the experimental value (66 GPa) given in [1]. The discrepancy may be due to two factors. First, the effects of friction between the fiber and matrix when the interface has debonded may have caused some discrepancy. The model used assumed a perfectly smooth, frictionless interface between the fiber and matrix, which may not be realistic. Second, the analysis assumes all the fiber-matrix interfaces are completely debonded, whereas, in the actuality all the fibers may not be debonded throughout the specimen. 
When the transverse stress in the elements in the $90^{\circ}$ plies reached a specified critical value, the material properties of the $90^{\circ}$ plies were modified to represent an isotropic material with an elastic modulus equal to the transverse modulus of the unidirectional laminate with a completely debonded interface. This, in effect, models the $90^{\circ}$ plies with a bilinear stress-strain curve. The critical transverse stress was chosen to be $155 \mathrm{MPa}$ based on experimental observations of unnotched [90] 8 laminates [1]. Thermal residual stresses, which were present in the experimental observations, were not included in the analyses.

The material model used in PAFAC is based on constituent properties, thus, the material properties required are the elastic modulus and Poisson's ratio for the fiber and matrix, and a stress-strain curve for the matrix. It is not possible, for example, to reduce the transverse modulus of one constituent to model interfacial failure. Nor is $i t$ possible to reduce the transverse modulus ( $E_{22}$ ) of an orthotropic material to model interfacial debonding of a $90^{\circ} \mathrm{ply}$. Thus, in order to simulate interfacial debonding with the PAFAC analysis, the $90^{\circ}$ plies with a debonded interface were modeled as isotropic plies with an elastic modulus equal to the transverse modulus of a unidirectional laminate with a completely debonded interface. This gave the debonded $90^{\circ}$ plies in the $[0 / 90]_{2 s}$ laminate an unrealistically low modulus in the axial fiber direction. The effect of this low modulus was found to be negligible (less than 2.58) on the stress-deformation response of the laminate. 
Table 1 - Constituent Properties For SCS-6/Ti-15-3

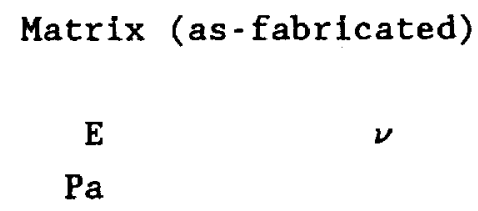
$9.239 \mathrm{E} 10$
.36

Fiber

$\begin{aligned} \mathrm{E} & \nu \\ \mathrm{Pa} & \end{aligned}$

$3.93 E 11 \quad .25$

Matrix Stress-Strain Curves (as-fabricated)

$\begin{array}{ll}\text { Strain } & \begin{array}{l}\text { Stress } \\ \mathrm{Pa}\end{array} \\ 0.0 & 0.0 \\ 0.0076 & 6.8948 \mathrm{E} 8 \\ 0.0082 & 7.4119 \mathrm{E} 8 \\ 0.0088 & 7.8428 \mathrm{E} 8 \\ 0.0094 & 8.2737 \mathrm{E} 8 \\ 0.0098 & 8.4461 \mathrm{E} 8 \\ 0.0106 & 8.7908 \mathrm{E} 8 \\ 0.0113 & 8.9632 \mathrm{E} 8 \\ 0.0118 & 9.0494 \mathrm{E} 8 \\ 0.0124 & 9.1356 \mathrm{E} 8 \\ 0.0132 & 9.2217 \mathrm{E} 8 \\ 0.0146 & 9.3079 \mathrm{E} 8 \\ 0.0168 & 9.3941 \mathrm{E} 8 \\ 0.0208 & 9.4803 \mathrm{E} 8\end{array}$




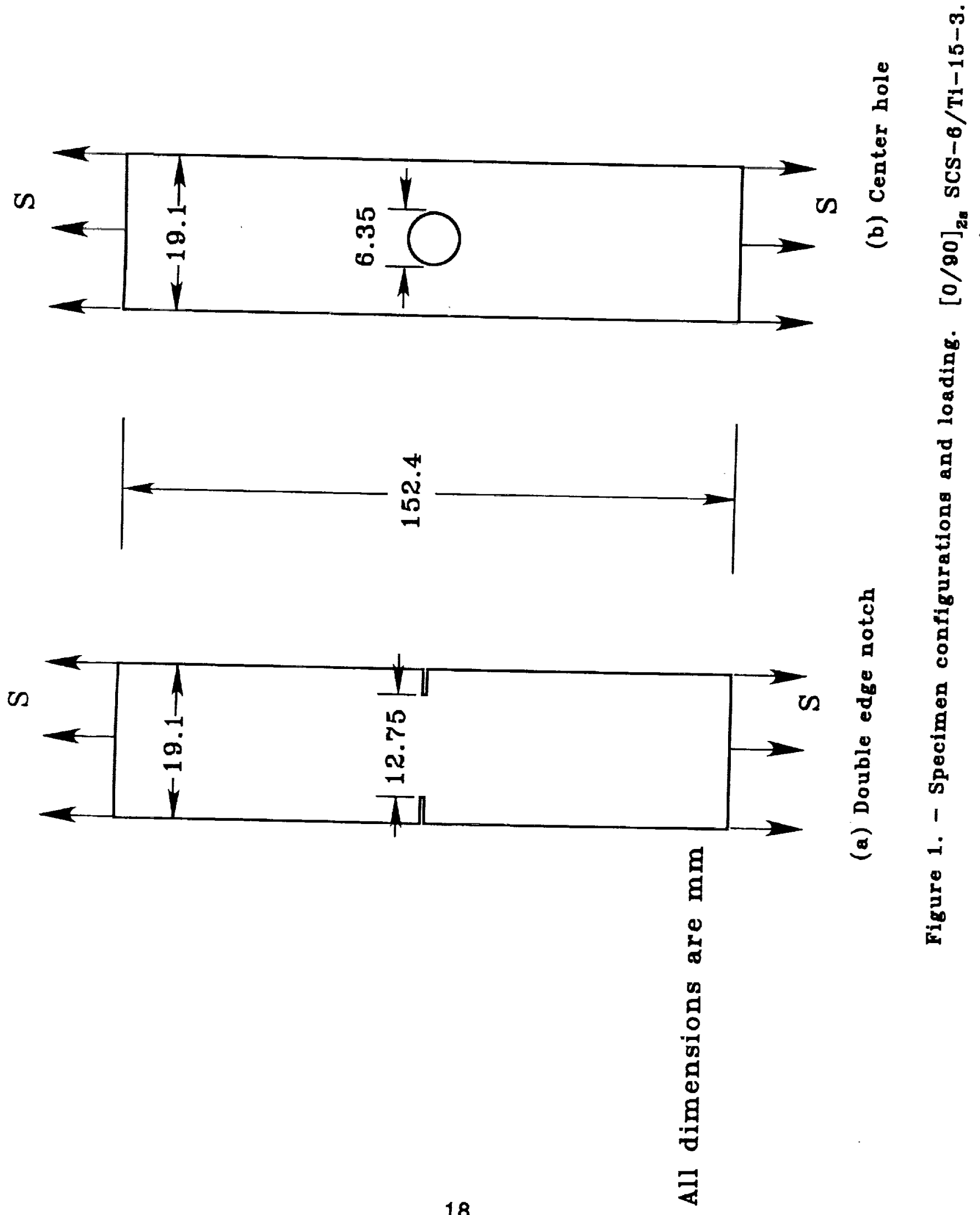




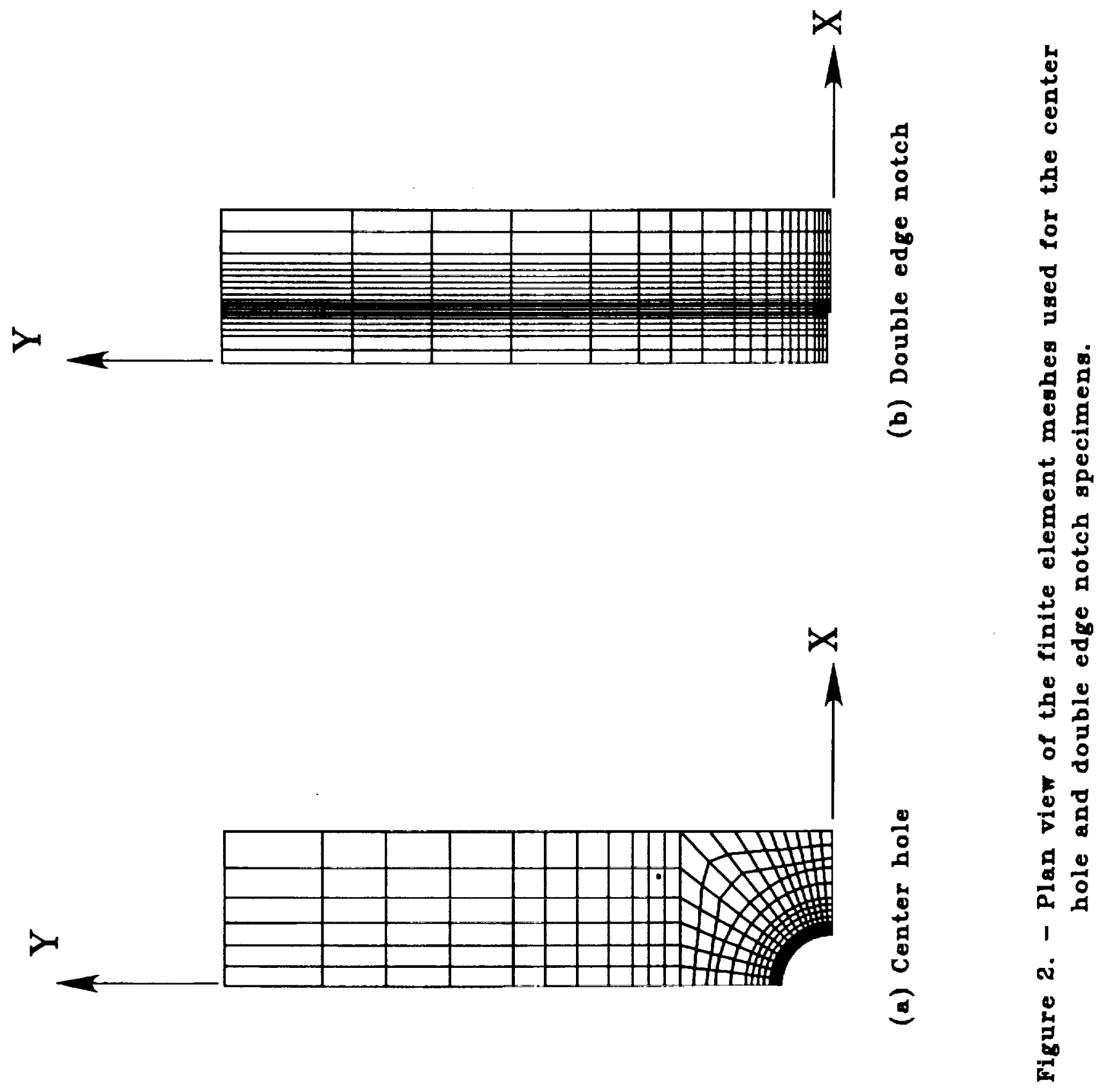




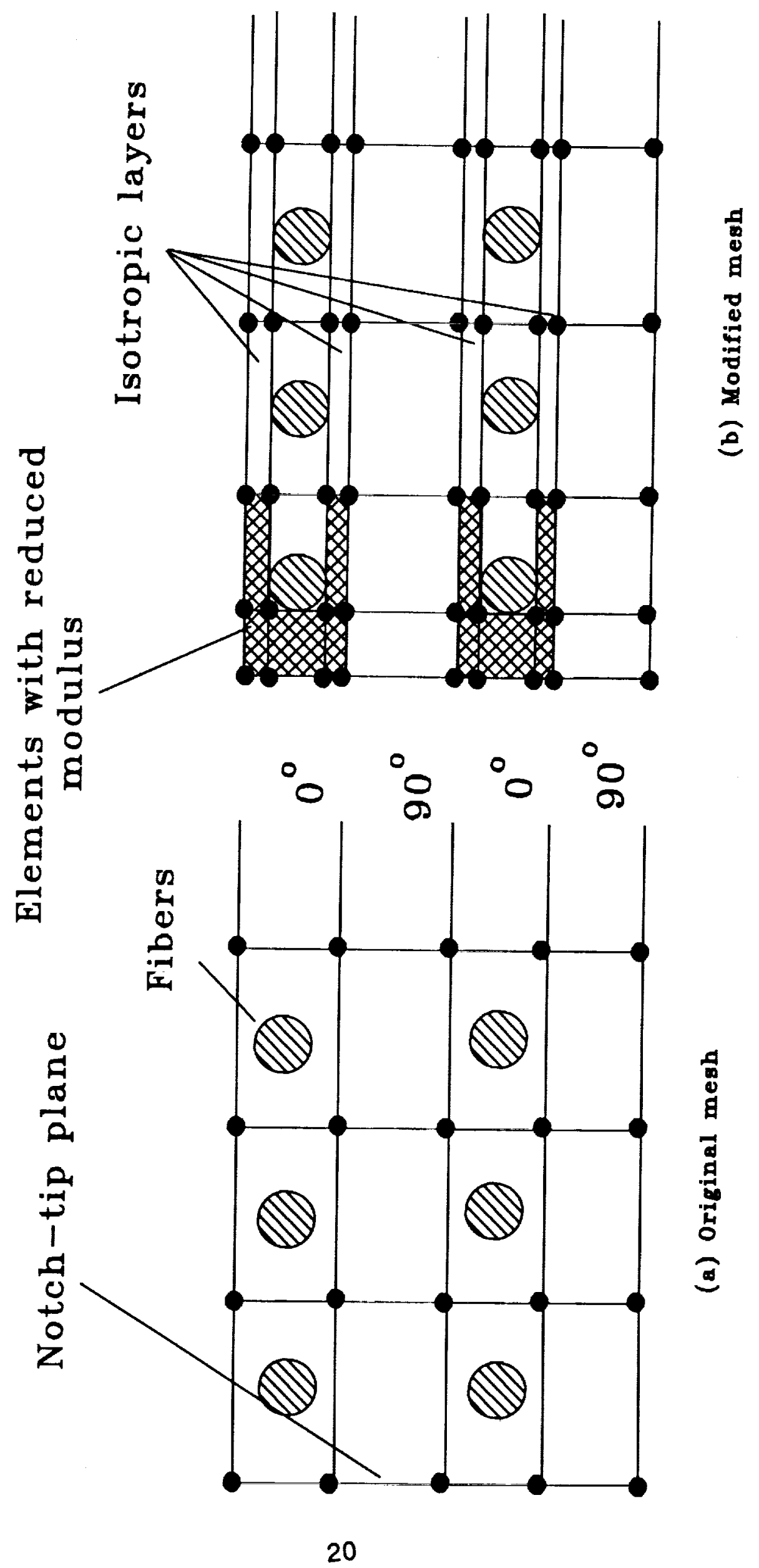

$\stackrel{8}{\circ}$

$\circ$

4

בే

1

ป

요

总

d

兽

ㄴ.

点

눙

苟

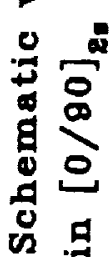

1 


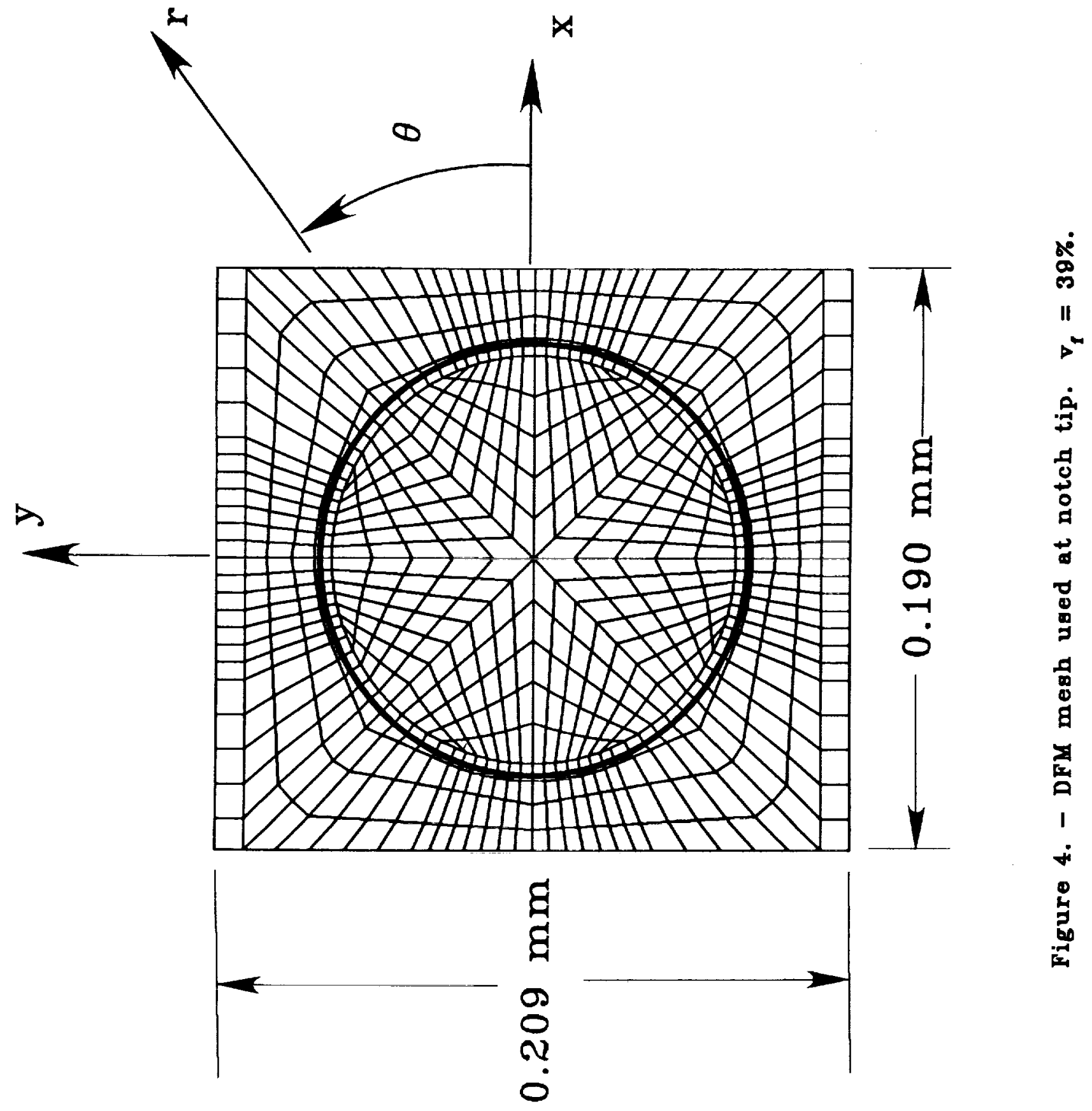




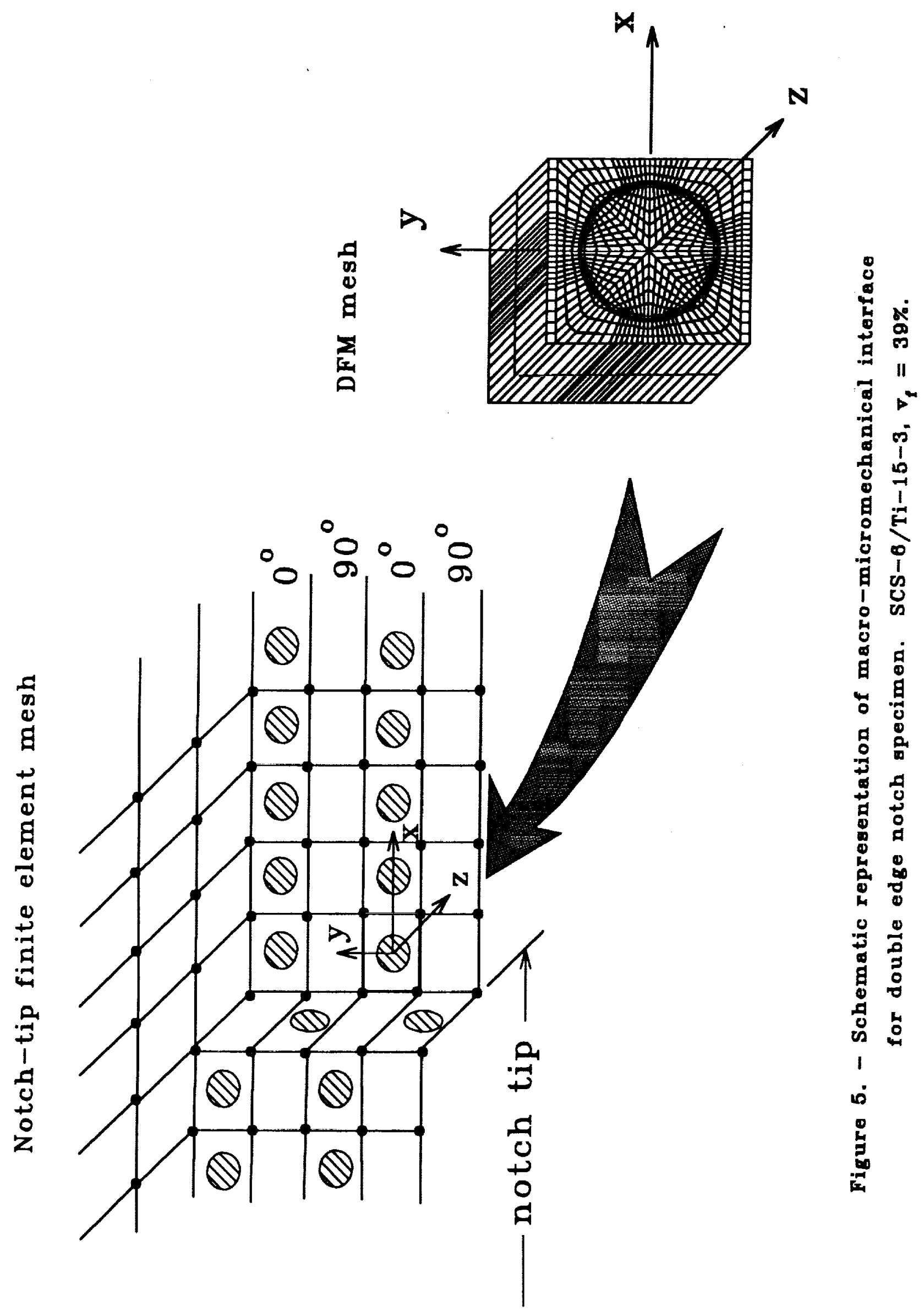



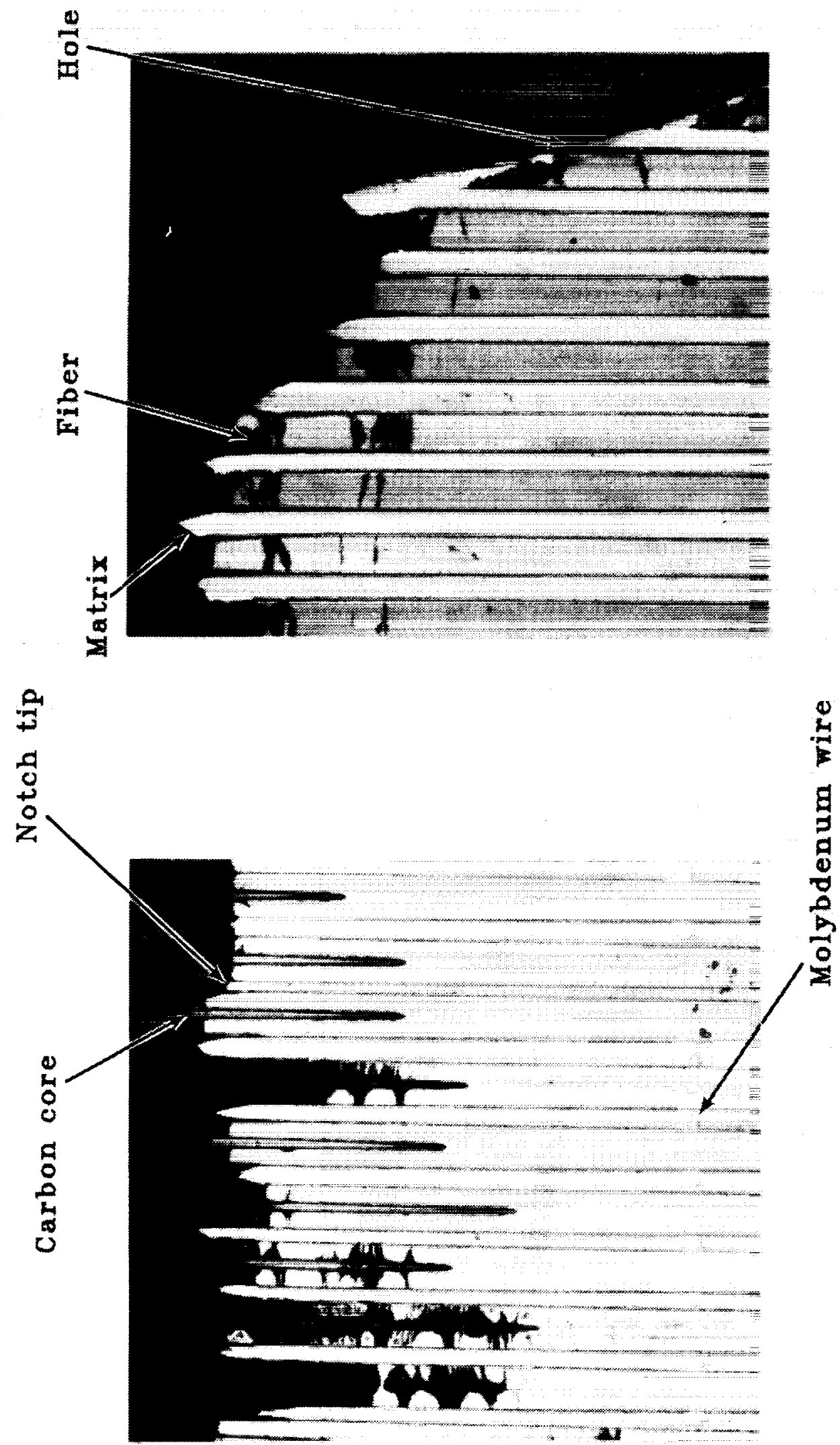

0
0
0
0
0
0
0
0
0
0
0
0
0
0
0
0
0
0
0
0 

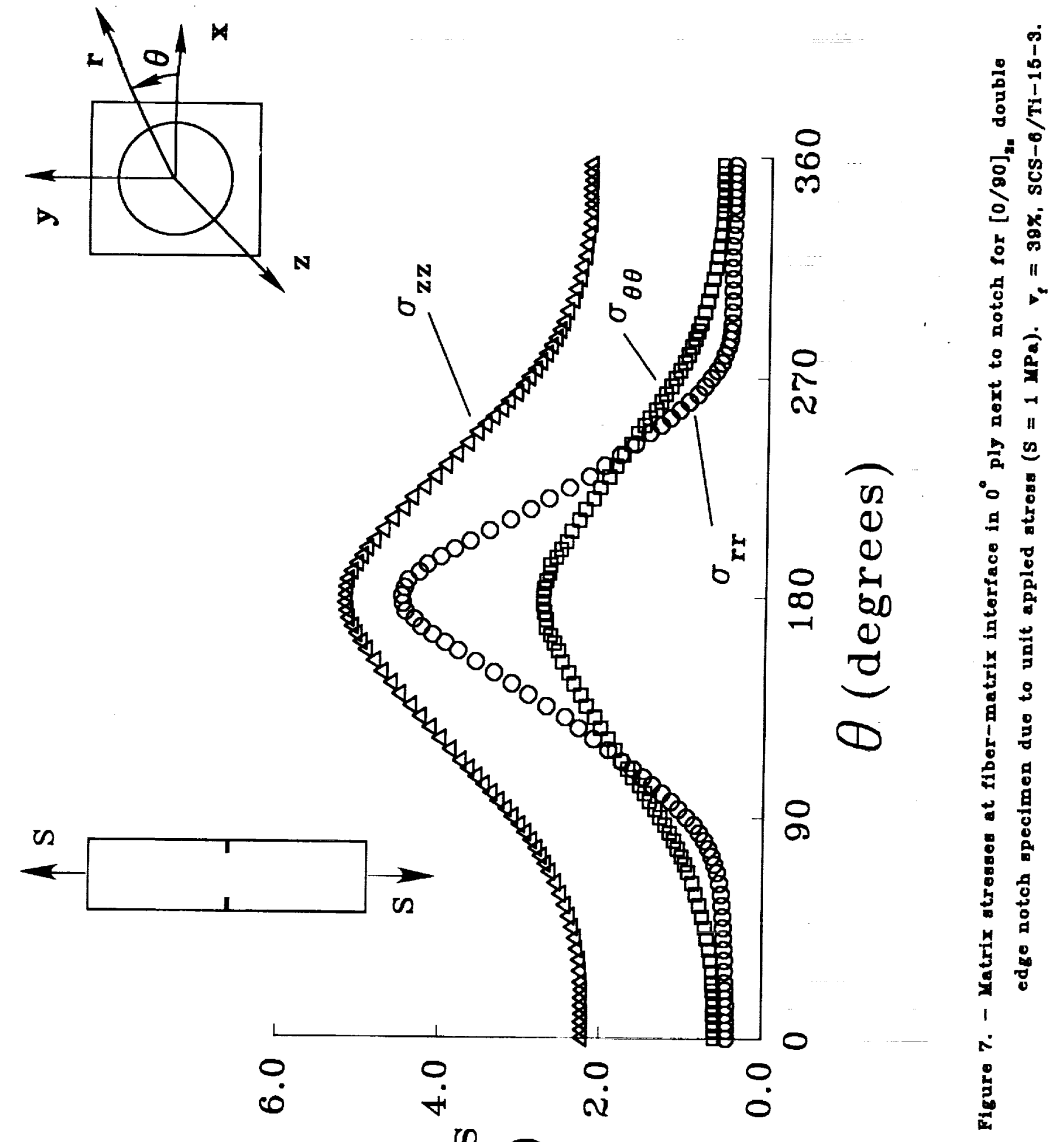

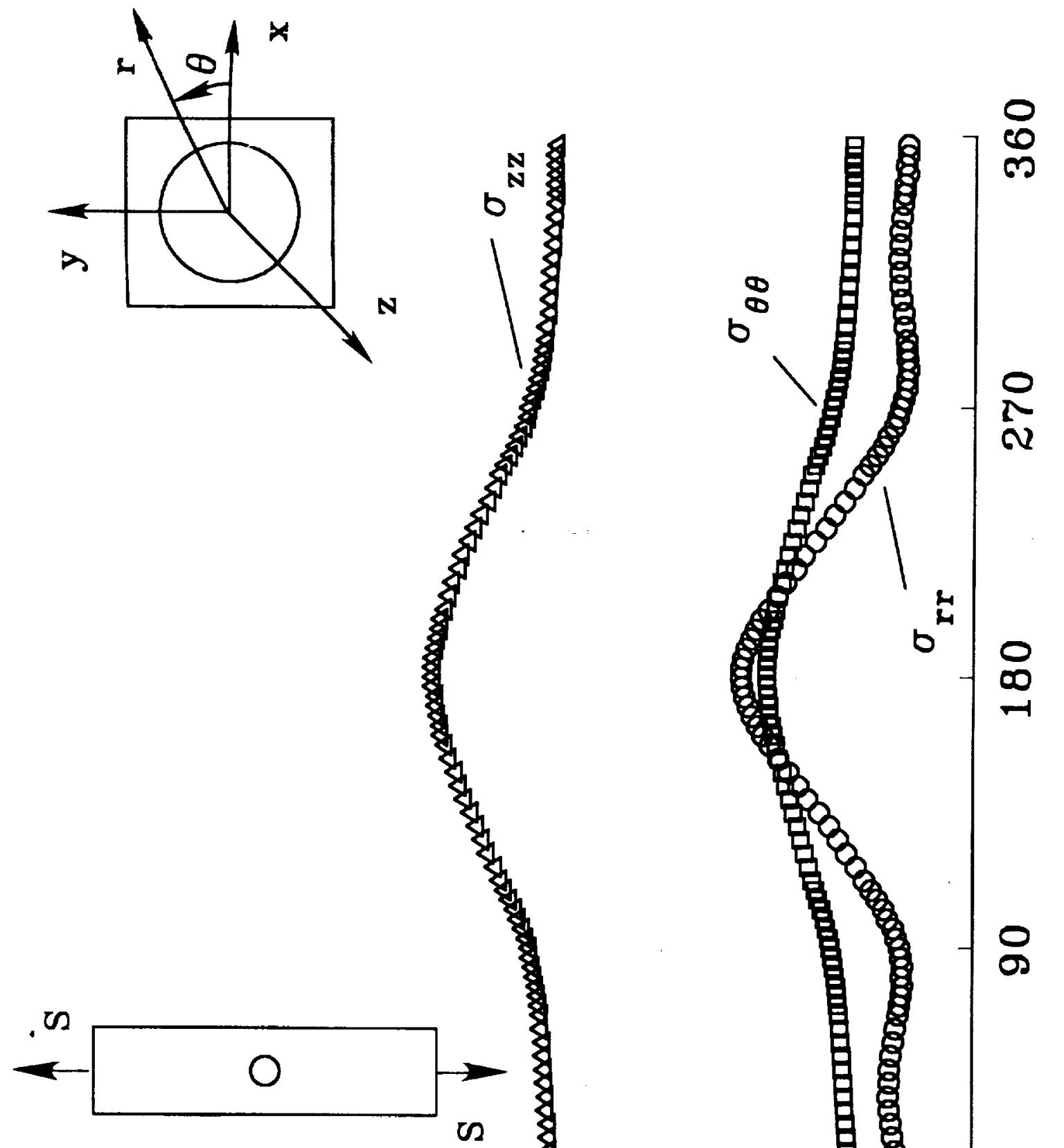

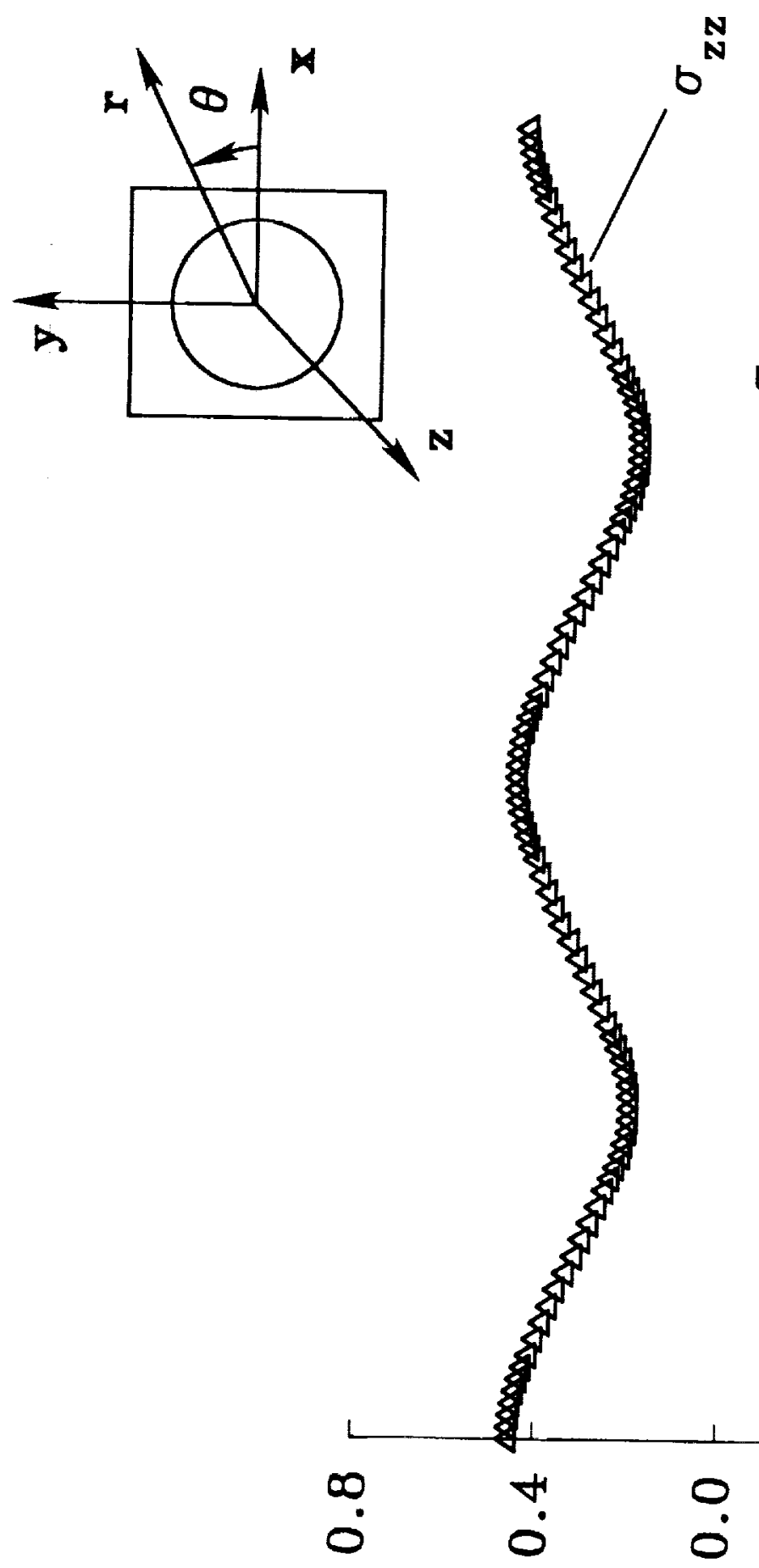


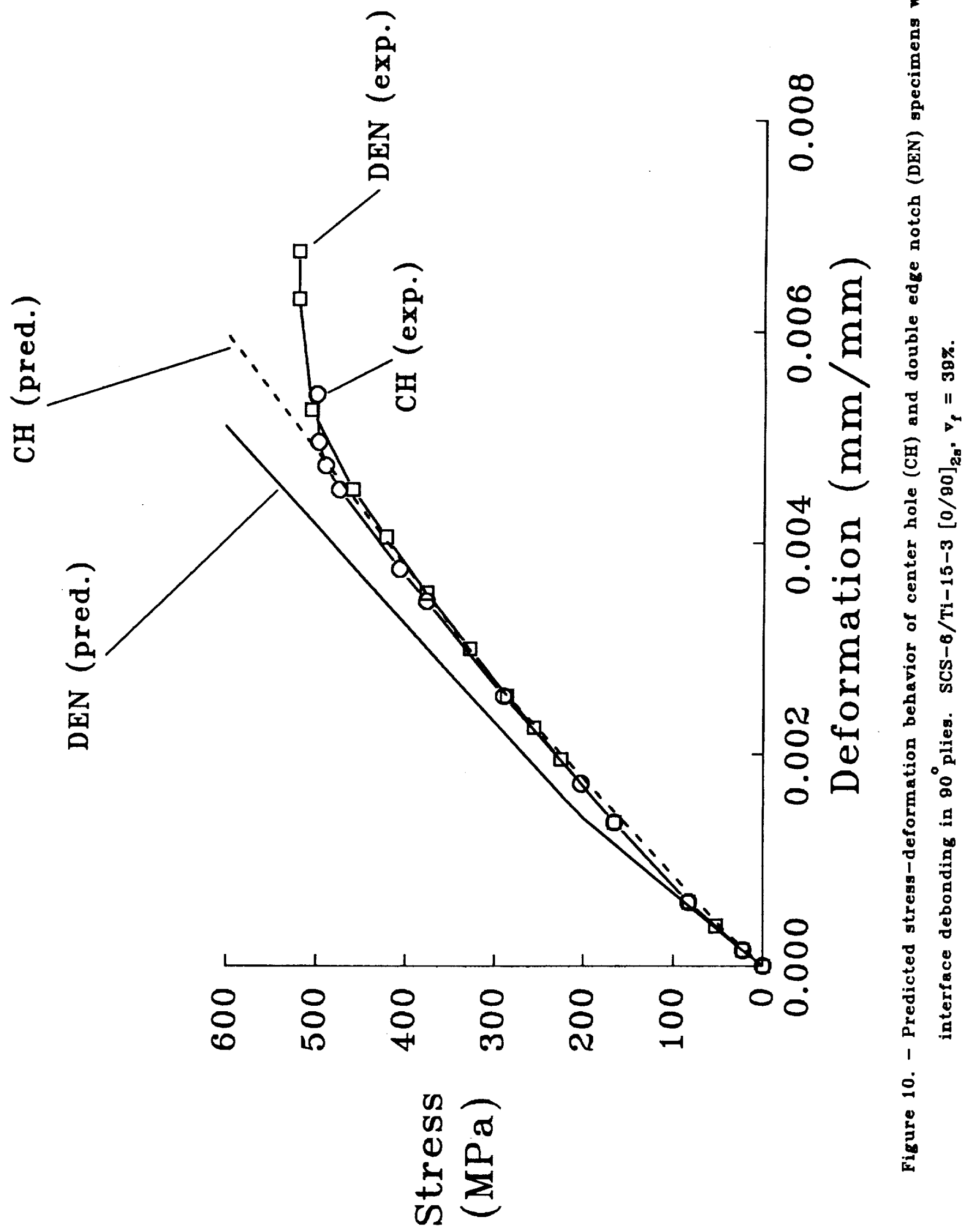



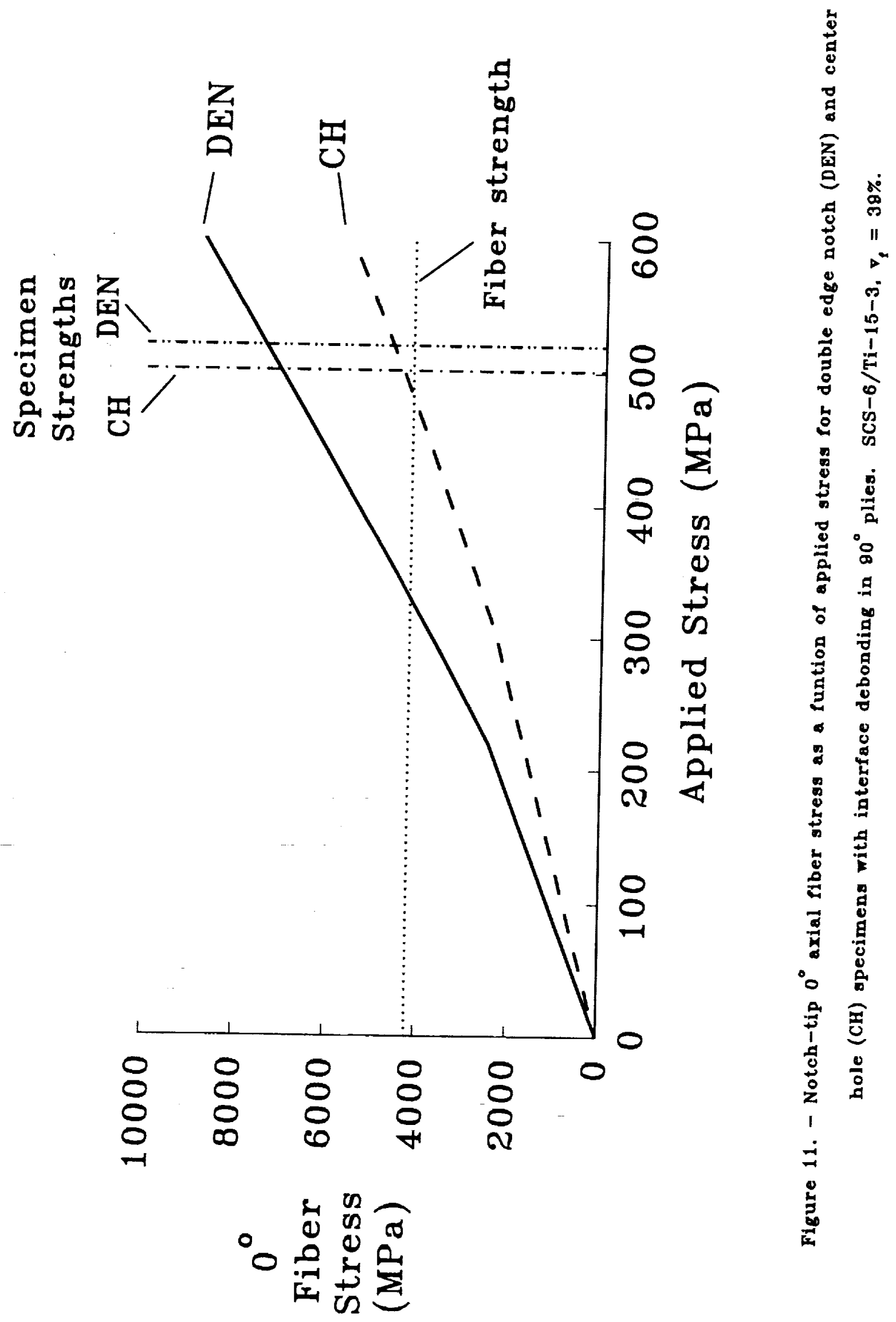


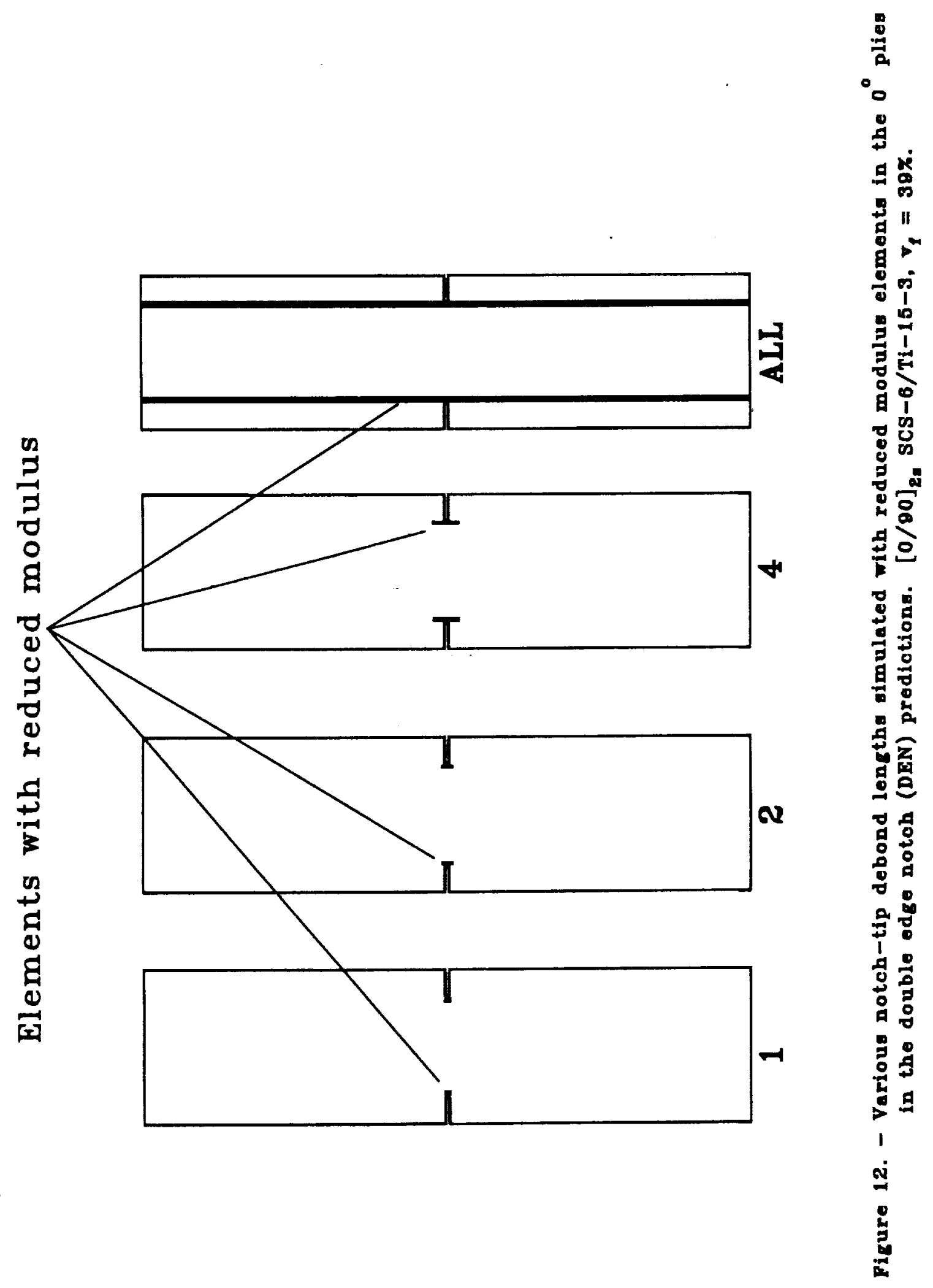




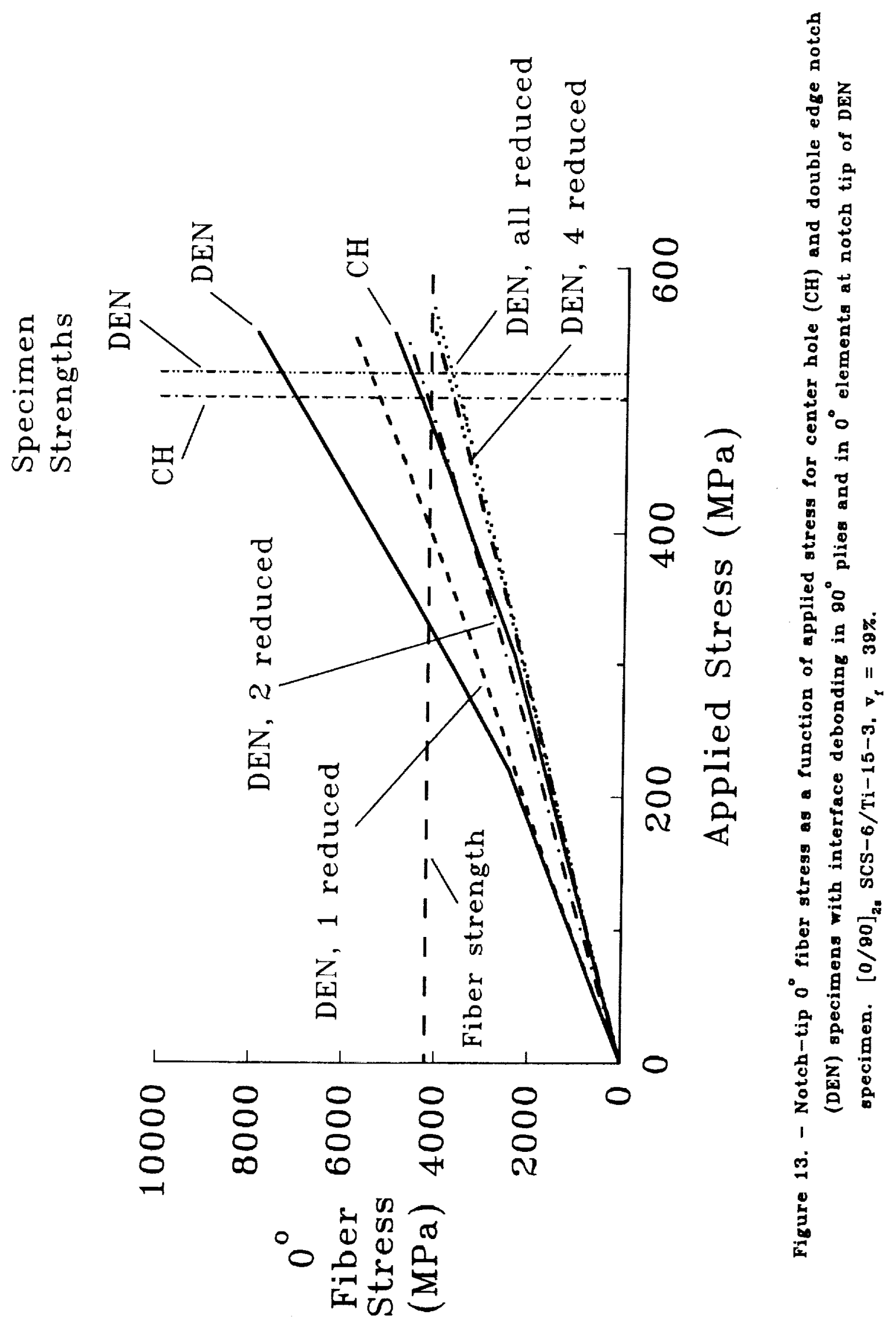




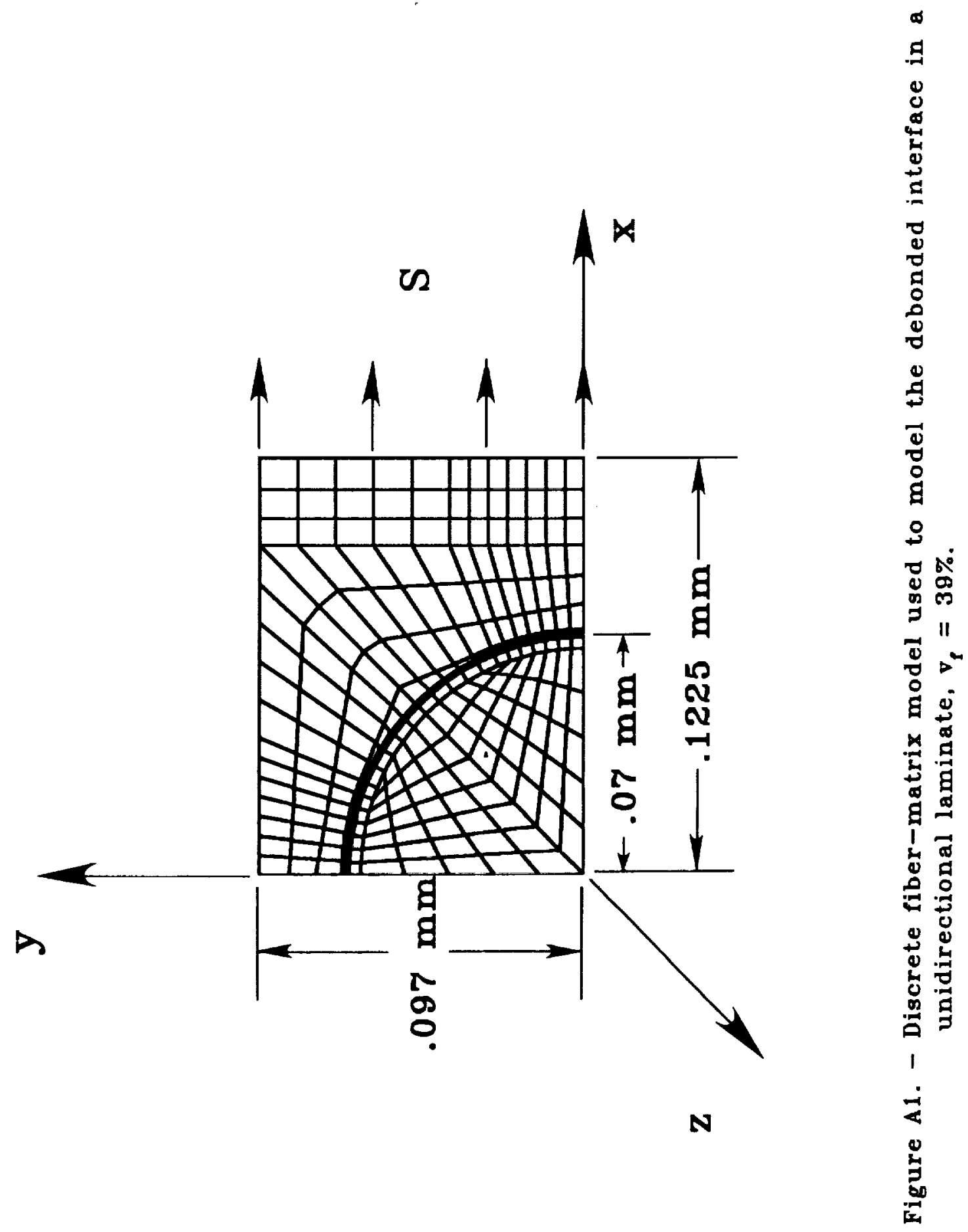




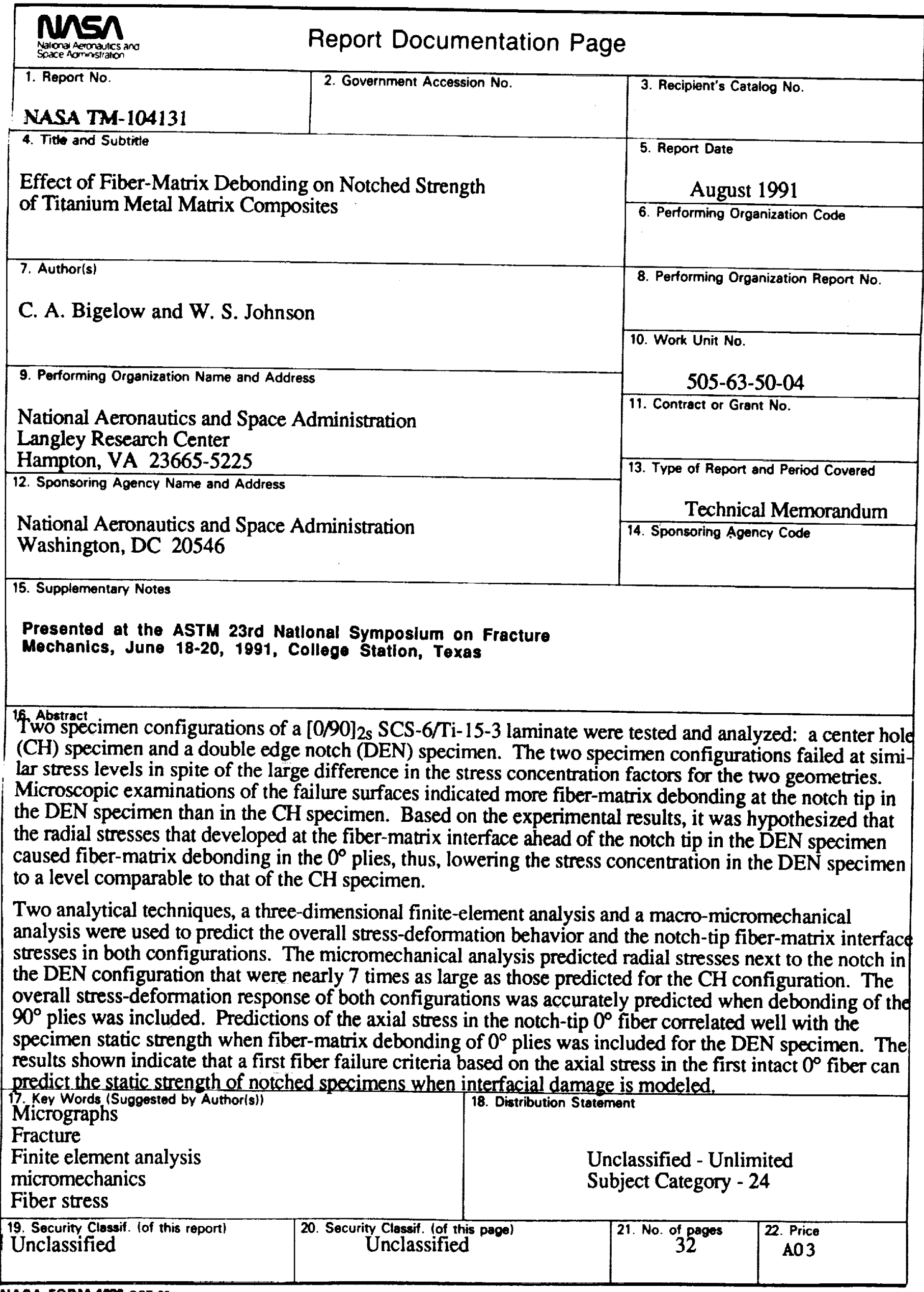

